\title{
CLASSICAL TRIGEMINAL NEURALGIA, PURELY PAROXSYMAL WITH VASCULAR COMPRESSION - A CASE REPORT
}

\author{
Elamathi B, Vijaya R., Valliappan V, Ramanathan A. Classical Trigeminal Neuralgia, Purely Paroxsymal With Vascular \\ Compression -A Case Report. Annal Dent Univ Malaya 2014; 21(1)
}

\begin{abstract}
According to the $3^{\text {rd }}$ edition of the international classification of headache disorders (ICHD3 2013), Trigeminal Neuralgia (TN) is classified into two types: 1. Classical TN, purely paroxysmal 2. Classical TN with concomitant persistent facial pain. In this article, the authors describe a 47 year-old, male with unilateral, severe, recurring, electric shock-like pain involving left lower jaw, teeth and gingiva. Diagnosis of classical TN of the left $3^{\text {rd }}$ division of the trigeminal nerve was made. The patient was treated with pharmacotherapeutic agents but without relief. Magnetic resonance imaging (MRI) of the brain showed medial vascular compression of left trigeminal pontine root entry zone caused by superior cerebellar artery. A microvascular decompression (MVD) surgery was done at the left trigeminal pontine root entry zone resulting in good relief of pain. This article highlights the differential diagnoses to be considered with TN and also emphasize the difference between the two types of the TN according to ICDH3 (2013). It also highlights the difference between classical TN purely paroxysmal with and without vascular compression by imaging techniques and their differing treatment modalities, which therefore should be reflected in future ICDH classification.
\end{abstract}

Keywords: Trigeminal neuralgia, ICDH3, MRI, superior cerebellar artery, microvascular decompression.

\section{INTRODUCTION}

Pain is defined as an unpleasant sensory and emotional experience associated with actual or potential tissue damage, or described in terms of such damage (1). Trigeminal neuralgia (TN) is considered to be one of the worst painful conditions affecting mankind. Neuralgia means pain in the distribution of a nerve or nerves (1). According to the $3^{\text {rd }}$ edition of the international classification of headache disorders (ICHD3) (2), TN is classified under painful cranial neuropathies and other facial pains. There are two types of TN recognized in this classification 1. Classical TN, purely paroxysmal (ICHD code - 13.1.1.1) 2. Classical TN with concomitant persistent facial pain (ICHD code - 13.1.1.2).

Trigeminal neuralgia is clinically described as the presence of sudden, brief, stabbing, severe pain provoked by light touch (innocuous stimuli) and occurring in attacks lasting few seconds (may be prolonged), with abrupt onset and termination usually on one side of the face (unilateral),

Case Report

\author{
Elamathi $B^{1}$, Vijaya $R .^{1}$, Valliappan $V^{2}$, Ramanathan \\ $A^{3,4}$ \\ ${ }^{1}$ Department of Anatomy, Meenakshi Medical \\ College and Research Institute, Kanchipuram, \\ TamilNadu. \\ ${ }^{2}$ Health Clinic Pandamaran, Ministry of Health, \\ Persiaran Raja Muda Musa, 42000, Klang \\ Selangor, Malaysia. \\ ${ }^{3}$ Oro-Maxillofacial Surgical and Medical Science, \\ Faculty of Dentistry, University of Malaya. \\ ${ }^{4}$ Oral Cancer Research and Coordinating Centre, \\ Faculty of Dentistry, University of Malaya.
}

\section{Corresponding Author: \\ Dr. Anand Ramanathan \\ Email:drranand@um.edu.my}

limited to the distribution of one or more divisions of the trigeminal nerve (usually $2^{\text {nd }}$ or/and $3^{\text {rd }}$ divisions of $5^{\text {th }}$ cranial nerve). The nature of pain is described as either shooting, stabbing, burning, excruciating or electric shocklike and unlike any other pain previously experienced by the person $(2,3)$.

The cause of pain in most patients of TN is thought to be due to the compression caused by the intracranial vessels on the trigeminal nerve root at or near the dorsal nerve root entry zone. However, the cause is not known in a small percentage of TN (4). Other causes of TN include tumor compression or intrinsic demyelination due to multiple sclerosis (5). There are three treatment modalities used for TN such as pharmacotherapy, surgery and a combination of pharmacotherapy and surgery. Pharmacotherapy is the first line of treatment for $\mathrm{TN}$ but the recurrence of pain in $\mathrm{TN}$ is common with this type of treatment in many patients. If MRI detects the offending vessel then microvascular decompression (MVD) surgery is a good option. However it carries some risk and is the last option carried out by the neurosurgeons. This article, presents a case of 47 yearold male with classical TN purely paroxysmal having the superior cerebellar artery compressing the left trigeminal pontine root entry zone. Differential diagnosis and treatment modalities (pharmacotherapeutic agents and surgical) are discussed highlighting the difference between classical TN purely paroxysmal with and without vascular compression (idiopathic). 


\section{CASE REPORT}

A 47 year-old, male presented with a history of severe, recurring, electric shock-like pain in the left lower jaw involving the teeth and the gingiva of the same region for a duration of 2 years in 2009. The pain did not cross the midline. The pain was aggravated by chewing, speaking, drinking fluids and contact with cold water on the face. Shaving his beard also caused episodes of pain to occur. The patient had initially responded to medication and had remission of pain. However, two years later he had persistent pain for three months and was on carbamazepine $150 \mathrm{mg}$ tid and baclofen $10 \mathrm{mg}$ tid, without relief. Past medical history revealed that the patient had undergone angioplasty and was under amilodipine, nebivolol and clopidogrel. A clinical diagnosis of classical trigeminal neuralgia of the left $3^{\text {rd }}$ division of the trigeminal nerve was made. Magnetic resonance imaging (MRI) of the brain in 2009 with Constructive Interference in Steady State (CISS) sequence shows cisternal segment of bilateral trigeminal nerve (Figure 1) and showed medial vascular compression of the left trigeminal pontine root entry zone caused by superior cerebellar artery (Figure 2). An MVD surgery was planned at the left trigeminal pontine root entry zone and carried out. The $5^{\text {th }}$ cranial nerve was found deeply indented on its ventral superior surface by a loop of the trunk of the left superior cerebellar artery. The superior cerebellar artery was moved away to a superior plane and it was held in this position by a piece of fluffy PTFE pledget and surgicel. The PTFE pledget was not in contact with the nerve. Post-operative recovery was uneventful and good. The post-operative MRI showed normal findings. The patient is relieved of the pain for the past 2 years and 5 months (December 2013).

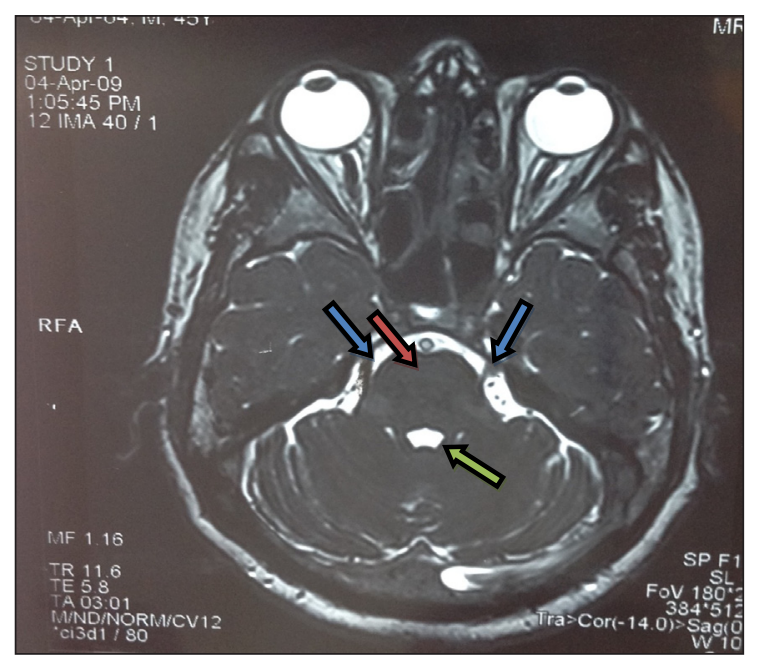

Figure 1: Constructive Interference in Steady State (CISS) MRI sequence shows cisternal segment of bilateral trigeminal nerve (blue arrows), pons (red arrow) and $4^{\text {th }}$ ventricle (green arrow)

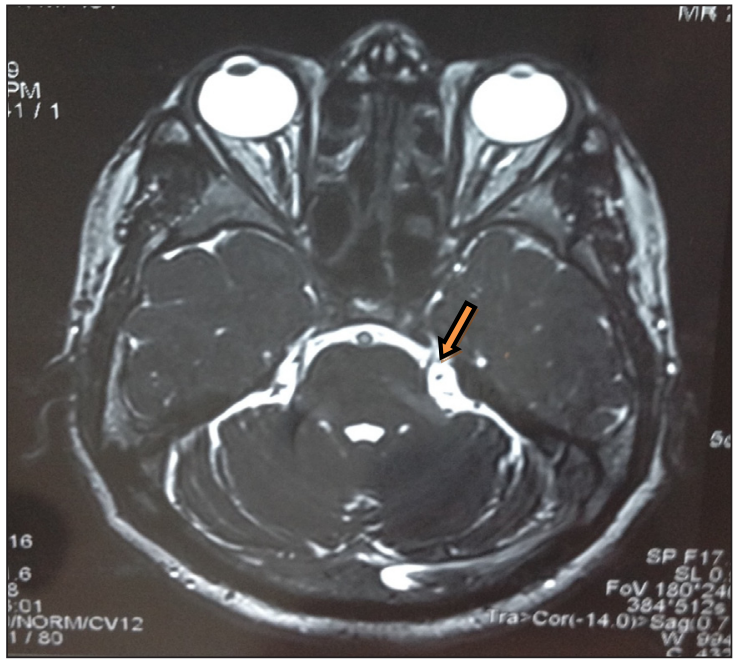

Figure 2: Constructive Interference in Steady State (CISS) MRI sequence shows left superior cerebellar artery (orange arrow) compressing the left trigeminal pontine root entry zone

\section{DISCUSSION}

Trigeminal neuralgia affects about 4.3 persons/100,000 annually (6). It commonly affects women more than men $(7,8)$ and persons in the $5^{\text {th }}$ and $8^{\text {th }}$ decade of life $(6-8)$. Our case was a male patient in $5^{\text {th }}$ decade. It should be noted that $\mathrm{TN}$ in young persons are considered to be secondary to either multiple sclerosis (MS) affecting the nerve (7) or tumors compressing the gasserian ganglion. Therefore careful evaluation of the patients less than 40 years of age for other neurological signs and symptoms and a thorough imaging of the brain needs to be carried out.

Trigeminal neuralgia is a clinical diagnosis (5). In all patients having unilateral facial pain, TN should be considered as a differential diagnosis (9). However, other differential diagnoses (Table 1) should be carefully evaluated and ruled out before arriving at the diagnosis of TN. This patient had all criteria pertaining to classical TN such as recurring, severe and electric shock-like pain precipitated by innocuous stimuli such as chewing, speaking, drinking fluids and contact with cold water on the face and even shaving his beard on the affected side of the face (trigger zone). Trigger zones are small areas present on the face, which are supplied by the affected division of the trigeminal nerve where minimal stimulation initiates a painful attack. These patients will be able to pinpoint these areas and try assiduously to avoid stimulating them. Trigger zones are pathognomonic of TN but not all cases with TN have trigger zones (9).

This patient had pain affecting the left side of the lower jaw, teeth and gingiva unilaterally involving the mandibular $\left(3^{\text {rd }}\right)$ division of the trigeminal nerve. According to the latest ICHD3, TN is classified into two types (Table 2 and 3). This patient had clinical criteria of classical TN. Moreover it was not associated 
Table 1: Differential diagnoses of Trigeminal neuralgia

\begin{tabular}{|c|c|}
\hline Diagnosis & $\begin{array}{l}\text { Characteristic features that differentiate } \\
\text { from trigeminal neuralgia }\end{array}$ \\
\hline $\begin{array}{l}\text { Dental pain (e.g., } \\
\text { caries, pulpitis, } \\
\text { periodontitis or } \\
\text { cracked tooth,) }\end{array}$ & $\begin{array}{l}\text { Localized sometimes referred, related } \\
\text { to hot or cold foods or biting; visible } \\
\text { abnormalities on oral examination (but } \\
\text { may not be visible in cracked tooth) }\end{array}$ \\
\hline $\begin{array}{l}\text { Temporomandibular } \\
\text { joint disorders }\end{array}$ & $\begin{array}{l}\text { Persistent pain; localized tenderness; jaw } \\
\text { abnormalities such as clicking sound }\end{array}$ \\
\hline $\begin{array}{l}\text { Myalgia of muscles } \\
\text { of mastication }\end{array}$ & $\begin{array}{l}\text { Persistent pain; localized tenderness of } \\
\text { one or more muscles of mastication }\end{array}$ \\
\hline Sinusitis & $\begin{array}{l}\text { Persistent pain associated with nasal } \\
\text { symptoms }\end{array}$ \\
\hline Otitis media & $\begin{array}{l}\text { Localized pain of ear with abnormalities } \\
\text { on examination and tympanogram }\end{array}$ \\
\hline $\begin{array}{l}\text { Postherpetic } \\
\text { neuralgia }\end{array}$ & $\begin{array}{l}\text { Continuous tingling pain involving only } \\
\text { one dermatome with history of herpes } \\
\text { zoster; often involving the first division }\end{array}$ \\
\hline Giant cell arteritis & $\begin{array}{l}\text { Persistent pain involving the temporal } \\
\text { region; often bilateral with jaw } \\
\text { claudication }\end{array}$ \\
\hline Cluster headache & $\begin{array}{l}\text { Longer-lasting pain involving orbital or } \\
\text { supraorbital region; may cause patient to } \\
\text { wake from sleep; autonomic symptoms }\end{array}$ \\
\hline $\begin{array}{l}\text { Glossopharyngeal } \\
\text { neuralgia }\end{array}$ & $\begin{array}{l}\text { Pain in throat, mouth or tongue caused by } \\
\text { swallowing, talking, or chewing }\end{array}$ \\
\hline Intracranial tumors & $\begin{array}{l}\text { Other neurologic symptoms or signs may } \\
\text { be present such as headache, seizures, } \\
\text { vision problem, vomiting etc. }\end{array}$ \\
\hline Migraine & $\begin{array}{l}\text { Longer-lasting pain associated with } \\
\text { photophobia and phonophobia; positive } \\
\text { family history }\end{array}$ \\
\hline Multiple sclerosis & $\begin{array}{l}\text { Eye symptoms and other neurologic } \\
\text { symptoms present such as loss of } \\
\text { sensitivity or changes in sensation, } \\
\text { numbness, muscle weakness, pronounced } \\
\text { reflexes, muscle spasm etc. }\end{array}$ \\
\hline $\begin{array}{l}\text { Trigeminal } \\
\text { neuropathy }\end{array}$ & Persistent pain associated sensory loss \\
\hline
\end{tabular}

with persistent facial pain between attacks. Therefore according to the ICHD3 (2), this patient has classical $\mathrm{TN}$, purely paroxysmal of the $3^{\text {rd }}$ division of trigeminal nerve. The authors like to emphasis here that it may be easier to diagnosis the classical TN purely paroxysmal as in this case but the $2^{\text {nd }}$ type of TN recognized by the ICDH3 classification, which has persistent facial pain of moderate intensity in the affected area may pose problems in diagnosis and it is necessary that clinicians are aware of this type of TN such that the patients are not misdiagnosed and receive proper treatment.

Trigeminal neuralgia mostly affects the right side of the face, the right side: left side ratio being 1.4:1 (7) the reason for the right side predilection is not known. In this case the site involved was the less common left side of the face. Trigeminal neuralgia mostly affects the $3^{\text {rd }}$ division as
Table 2: ICHD3 2013 diagnostic criteria for classical trigeminal neuralgia (2)

A At least three attacks of unilateral facial pain fulfilling criteria $\mathrm{B}$ and $\mathrm{C}$.

B Occurring in one or more divisions of the trigeminal nerve, with no radiation beyond the trigeminal distribution.

C Pain has at least three of the following four characteristics Recurring in paroxysmal attacks lasting from a fraction of seconds to 2 minutes.

Severe intensity.

Electric shock-like, shooting, stabbing or sharp in quality. Precipitated by innocuous stimuli to the affected side of the face.

D No clinically evident neurological deficit.

E Not better accounted for by another ICHD-3 diagnosis.

Table 3: ICHD3 2013 diagnostic criteria for both types of classical trigeminal neuralgia (2)

\begin{tabular}{clc}
\hline & Purely paroxysmal & $\begin{array}{l}\text { With concomitant persistent } \\
\text { facial pain }\end{array}$ \\
\hline A & $\begin{array}{l}\text { Recurrent attacks of unilateral facial pain fulfilling criteria } \\
\text { for Classical trigeminal neuralgia (Table 1) }\end{array}$ \\
B & $\begin{array}{l}\text { No persistent facial pain } \\
\text { between attacks }\end{array}$ & $\begin{array}{l}\text { Persistent facial pain of } \\
\text { moderate intensity in the } \\
\text { affected area }\end{array}$ \\
C & Not better accounted for by another ICHD-3 diagnosis. \\
\hline
\end{tabular}

in this case followed by the $2^{\text {nd }}$, combination of the $3^{\text {rd }}$ and $2^{\text {nd }}$, rarely the $1^{\text {st }}$ and combination of $1^{\text {st }}$ and $2^{\text {nd }}$ divisions of the trigeminal nerve (7).

Once the diagnosis of the TN is made then the first line of treatment is pharmacotherapy. Carmabezipine is the drug of choice for treatment of TN and has been found to be successful in most cases and no other medication has shown to be superior in large studies, meta-analysis and Cochrane reviews $(10,11)$. Initial treatment for patients with TN purely paroxysmal is carbamazepine with the recommended dosage ranging from 100 to $1,200 \mathrm{mg} /$ day and most patients responding to 200 to $800 \mathrm{mg}$ /day in two or three divided doses. Carbamazepine has side effects such as dizziness and unsteadiness that are not tolerated by the patients (5) and sometimes they may not respond to it. Hence, if unsuccessful or if it provides only partial relief or is not tolerated then other drugs may be used. There are many drugs, which have been used either alone or in combination with limited success (Table 4). Most patients are reported to respond, at least temporarily, to single or combination therapy with these pharmacotherapeutic agents (9). This patient was taking a combination of carbamazepine and baclofen with poor response.

Therefore the option of MVD was explored in this patient. The most celebrated treatment modality for treating TN has been MVD by the neurosurgeons (16). It is the sole therapy that addresses the presumed pathology of this condition. 
Table 4: Pharmacotheraputic agents used in treatment of trigeminal neuralgia

\begin{tabular}{ll}
\hline Pharmacotheraputic agents & Dosage/day \\
\hline Valproic acid (12) & 800 to $1600 \mathrm{mg}$ \\
\hline Baclofen (13) & 60 to $80 \mathrm{mg}$ \\
Pimozide (13) & $4-10 \mathrm{mg}$ \\
Topical capsaicin (14) & $\mathrm{NA}^{*}$ \\
\hline Lamotrigine (12) & $200-400 \mathrm{mg}$ \\
\hline Fosphenytoin (13) & $500-1000 \mathrm{mg}$ \\
Topiramate (12) & $50-100 \mathrm{mg}$ \\
\hline Gabapentin (13) & $1000-1200 \mathrm{mg}$ \\
Clonazepam (15) & $1.5-6 \mathrm{mg}$ \\
\hline Botulinum toxin type A (13) & $100 \mathrm{units}$ \\
Sumatriptan (sc) ${ }^{+}(13)$ & $3 \mathrm{mg}$ \\
\hline Intranasal lidocaine $8 \%(13)$ & $0.2 \mathrm{ml}$ \\
\hline
\end{tabular}

*NA - not available

+ sc - subcutaneous

Jannetta (17) is credited with the modern concept of vascular compression as the underlying pathology resulting in $\mathrm{TN}$ on the basis of his explorative finding of the trigeminal complex in the posterior fossa through operating microscope. Surgery is indicated when pharmacotherapy does not produce expected results or if patient cannot tolerate it (8). However, it should be noted that MVD is indicated only in TN purely paroxysmal with aberrant vessels shown in MRI (8). Trigeminal neuralgia with concomitant persistent facial pain (Type 2) and TN purely paroxysmal but idiopathic are contraindicated for this procedure. Therefore the authors are of the opinion that TN purely paroxysmal with and without (idiopathic) vascular compression has to be differentiated since the treatment options for the former includes MVD and pharmacotheraputic agents whereas the later is limited to pharmacotherapeutic agents and this should be reflected in future ICDH classification. In this patient MRI showed vascular compression by superior cerebellar artery on the left trigeminal pontine root entry zone therefore MVD was opted and resulted in good prognosis. Low recurrence and sensory loss is seen in MVD when compared to other surgical treatment modalities (16).

\section{CONCLUSION}

The diagnosis of TN should be carried out with meticulous history taking and considering other differential diagnosis. Once diagnosis of TN purely paroxysmal is made the treatment with pharmacotherapeutic agents should be considered as the $1^{\text {st }}$ line of treatment failing which MVD can be considered if MRI shows intracranial vascular compression. However, if MRI shows intracranial vascular compression it may be necessary to consider MVD as the $1^{\text {st }}$ option of therapy before pharmacotherapy but this needs to be validated with long term interventional studies. Therefore, it is necessary to recognize classical TN purely paroxysmal with and without vascular compression by imaging techniques since the treatment modalities differ between these types of TN, moreover this should be reflected in future ICDH classification.

\section{ACKNOWLEDGEMENTS}

The authors would like to thank the surgeons involved in this case for their contribution.

\section{REFERENCES}

1. Merskey H and Bogduk M. Part III: Pain terms. A current list with definitions and notes in usage. In Merskey $\mathrm{H}$ and Bogduk M (Eds.), Classification of chronic pain, IASP task force on taxonomy. $2^{\text {nd }} \mathrm{ed}$. Seattle, WA: IAPS press. 1994; 209-14.

2. Headache Classification Committee of the International Headache Society (IHS). The International Classification of Headache Disorders, 3rd edition (beta version). Cephalalgia 2013; 33(9):774-86.

3. Trigeminal Neuralgia Association UK. Trigeminal neuralgia an overview. 2011; $1-8$.

4. Hamlegn PJ and King TT. Neurovascular compression in trigeminal neuralgia-A clinical \& anatomical study. J Neurosurg 1992; 76; 548-54.

5. Fan Y-W. Management of Trigeminal Neuralgia. The Hong Kong Medical Diary. 2006; 11(12):3-4.

6. Katusic S, Beard CM, Bergstralh E, Kurland LT. Incidence and clinical features of trigeminal neuralgia, Rochester, Minnesota, 1945-1984. Ann Neurol 1990; 27: 89-95.

7. Loh HS, Ling SY, Shanmuhasuntharam P, Zain R, Yeo JF, Khoo SP. Trigeminal neuralgia. A retrospective survey of a sample of patients in Singapore and Malaysia. Aust Dent J. 1998; 43(3):188-91.

8. Gupta SK, Gupta A, Mahajan A, Gupta R, Tandon VR, Gupta N (2005). Clinical Insights in Trigeminal Neuralgia. JK Science 2005; 7(3): 181-4.

9. Krafft RM. Trigeminal Neuralgia. Am Fam Physician. 2008; 77(9):1291-6.

10. McQuay H, Carroll D, Jadad AR, Wiffen P, Moore A. Anticonvulsant drugs for management of pain: a systematic review. BMJ. 1995; 311:1047-52.

11. Wiffen PJ, McQuay HJ, Moore RA. Carbamazepine for acute and chronic pain. Cochrane Database Syst Rev. 2005; 20;(3): CD005451. 
12. George M, Selvarajan S, Indumathi C. Drug therapy for Trigeminal Neuralgia. e-J Dent. 2011; 1(2): 2831.

13. Genese F, Goldstein LB. Part Two: Trigeminal Neuralgia: A closer look at this enigmatic and debilitating disease. Pract Pain Manage. 2012; 12(8): $1-8$.

14. Epstein JB, Marcoe JH. Topical application of capsaicin for treatment of oral neuropathic pain and trigeminal neuralgia. Oral Surg Oral Med Oral Pathol. 1994; 77(2):135-40.
15. Sheinberg MA and Sagher O. Medical management of trigeminal neuralgia in surgical management of pain edited by Burchiel K, Thieme. 2002; 304-10.

16. Elias WJ and Burchiel KJ, (2004). Trigeminal Neuralgia: Microvascular Decompression. In Pain Management for the Neurosurgeon: Part 2; Editor in Chief, Fisher WS; Guest Editor, Burchiel KJ. Seminars in Neurosurg. 2004; 15(2/3): 143-50.

17. Jannetta PJ. Arterial compression of the trigeminal nerve at the pons in patients with trigeminal neuralgia. J Neurosurg. 1967; 26: 159-62. 